\title{
TOWARDS A KARST ASSESSMENT STANDARD PRACTICE
}

\author{
Robert K. Denton Jr., CPG, CPSS \\ GeoConcepts Engineering Inc, 19955 Highland Vista Dr., Ste. 170, Ashburn, Virginia 20147 USA, \\ rdenton@geoconcepts-eng.com
}

\begin{abstract}
The assessment of karst conditions and putative karst geohazards prior to residential and commercial development is currently in its infancy, from a scientific aspect. Borrowing from the medical lexicon, most karst features at proposed building sites are dealt with using an approach wherein the "symptoms and conditions" are treated (e.g. sinkhole remediation), often only after site development activities have commenced. If karst hazards are suspected, roadways, foundations and specific at-risk areas may be investigated using various geophysical methods; however the results of these investigations require specialized knowledge to be interpreted and understood. Thus stakeholders without geological training may find the investigator's results indecipherable, often leading to unnecessary and expensive supplemental studies, the need for which is entirely based on the non-technical stakeholder's faith in the investigator's judgment.
\end{abstract}

In contrast, a recent trend among consulting firms is to attach cursory karst "assessments" to due diligence study reports, particularly Phase I Environmental Site Assessments. These combined assessments are often performed by individuals who are inexperienced in geology, often without any specific training in karst geology. Not unexpectedly, this can lead to numerous mistakes, errors, and oversights. More troubling, these studies often report a lack of karst risks at the site under study, a result that the stakeholders may initially embrace, but which later can result in substantial financial loss and/or significant threats to human health and the environment.

To address these concerns, we propose a proactive, "preventative" standard practice for karst assessments. Ideally, this proactive approach will help to delineate potential karst hazards so that they can be avoided, managed, or corrected by remediation. Requirements for investigators, a proposed scope of services, fieldwork and data review checklist, and a template for a follow-up karst management plan are presented.
It is our hope that if carried out and reported accurately, the proposed assessments should allow even a nontechnical stakeholder to make informed decisions regarding the relative risk of karst geohazards, the need for further studies, and potential corrective actions that site development may entail.

\section{Introduction and Background}

The study of karst features, in particular karst springs and groundwater stretches back into earliest written human history. One of the first formal descriptions of caves and their hydrography was written in 221 B.C.E. in China, and the solution process of carbonate rocks was described accurately by the Roman Philosopher Seneca (4 B.C.E. -65 C.E.). Commentary by naturalists and philosophers on karst features and hydrology continued in both Europe and Asia through the subsequent centuries and entered into the era of systematic geomorphological investigation in the $19^{\text {th }}$ century (LaMoreaux and LaMoreaux, 1998).

Not surprisingly, in regions where much of the land surface was underlain by soluble bedrock and prone to the development of karst terrain, karst studies were advanced by the interests of regional politics (Zötl, 1974). One such area was central Europe, where the Austro-Hungarian Empire had acquired extensive tracts of karst lands. The need to ensure that water supplies were adequately developed and infrastructure was protected drove these studies forward, and arguably the Austrian studies could be considered the first examination of karst as a geohazard, in particular Cvijić's 1893 monograph Das Karstphänomen. Nevertheless, the majority of interest in karst remained of a purely scientific nature, and there was little emphasis on assessing the environmental and economic impacts of human development in karst terrains until the latter half of the $20^{\text {th }}$ Century (LaMoreaux, et al, 1975; Moser and Hyde, 1974; Rauch and Werner, 1974).

An increased sense of environmental awareness, coupled with increasing residential and commercial development in karst terrains during the 1970s and 1980s led to increased interest in the characterization and mitigation 
of karst hazards and environmental impacts. The Center for Cave and Karst Studies at Western Kentucky University was one of the first programs in the United States specifically created to deal with karst, from both scientific and engineering aspects. At a national level, the importance of karst studies was heralded by the creation of the National Cave and Karst Research Institute (NCKRI).

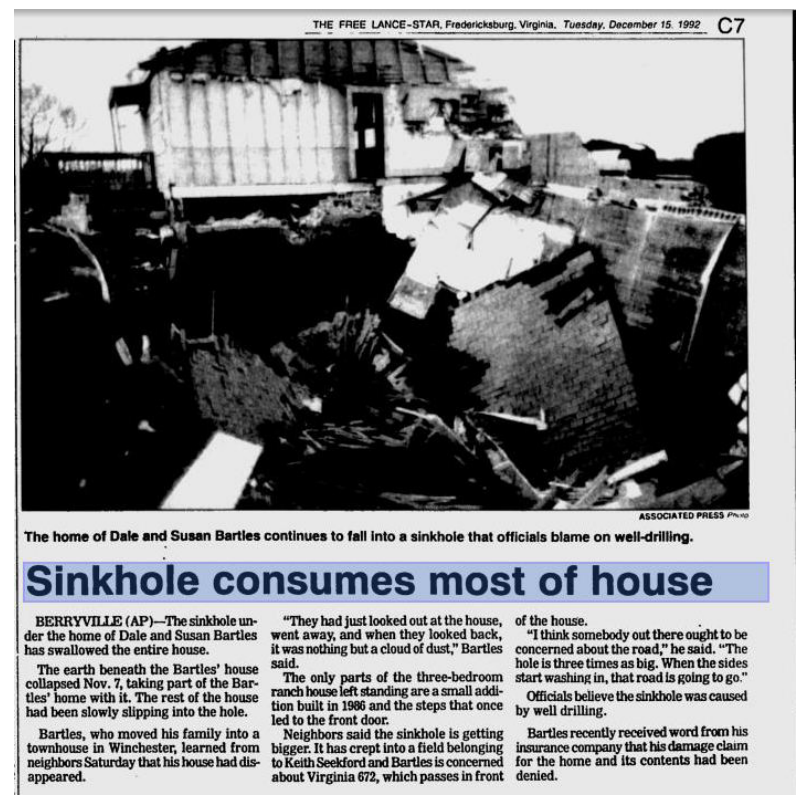

Figure 1. A Virginia newspaper story detailing the 1992 collapse of a house in the Shenandoah Valley into a sinkhole.

Simultaneously, local jurisdictions began to respond to karst geohazard issues on their own, driven by various incidents that brought caves and karst to the forefront of public interest. (Figure 1).

As a result of this increased public interest and concern, a series of karst model ordinances were proposed at both state and county levels across the United States (Karst Portal, 2012). Typically, these model ordinances dealt with the "what" and "where" of karst, but not the "who" and "how". Karst studies were increasingly being required by planning boards and zoning commissions as part of the studies for approval and permitting of residential and commercial development in potential karstlands, but the manner in which the studies were conducted, and the necessary qualifications of the investigators, was typically not specified.

During the last decades of the $20^{\text {th }}$ century there was a veritable renaissance in academic studies regarding speleogenesis, karst hydrology and karst biology, yet ironically there was little attempt to advance the development of a "karst site assessment" as a standard practice. The putative process languished at the same stage of evolution as environmental site assessments prior to the creation of the specific due diligence scope of work codified in the American Society of Testing and Materials (ASTM) E1527 practice. Karst "assessments" ranged in nature from cursory sinkhole inventory and rudimentary geophysical subsurface investigation (often without any interpretation), to geologically detailed and often indecipherable "all-inclusive" investigations, none of which would assist municipal planners, regulators and/or developers in making well-informed decisions. Frequently the lack of any obvious surface karst features (e.g. sinkholes or caves) would result in a finding by the investigator(s) that there were "no karst issues" at a site. In contrast, investigators might recommend lengthy and detailed follow-up studies where none were warranted. Errors and misstatements of these sorts made karst studies misleading and essentially useless for responsible development and land planning.

\section{Towards a Standard of Practice}

In response to the polyglot of assessment schemes a movement towards a karst assessment "standard of practice" began to take form in the first decade of the $21^{\text {st }}$ century. Notable examples were the Virginia Sinkhole Classification Scheme for Land Use Planning (Orndorff, et al, 2001), Kentucky Model Karst Ordinance (Currens, 2009), the Clarke County Virginia Sinkhole Ordinance (Code of Clarke County, 1997) and Karst Plan Requirements (Teetor, 2004), and Chapter 6 of the Loudoun County Virginia Facility Standards Manual - Limestone Overlay District (2010). Nevertheless, a single karst assessment standard of practice similar to the ASTM standard practice for Environmental Site Assessments (ASTM, 2005) was lacking.

Thus, what we present in this article is a proposed model standard of practice that embodies a set of basic elements that should be included in any karst site characterization. It must be emphasized that this approach is not to be considered the exclusive requisite elements in a karst assessment, but the essential starting points for a basic (preliminary) evaluation. Karst assessments will vary according to the needs of the user(s), the requirements embodied in local ordinances and the scope and nature of the proposed development. However, if performed 
in accord with this scheme, and reported accurately, the proposed assessments should allow even a non-technical stakeholder to make informed decisions regarding the relative risk, the need for further studies, and potential corrective actions that site development may entail.

\section{Requirements for Karst Investigators}

Based on jurisdictions that have requirements for karst investigations, the recommended minimum qualification for the karst professional investigator is as follows:

A Professional Engineer (PE) with a geotechnical (civil) engineering specialty and 5-years of experience in karst geology and/or hydrology; (or)

A Certified Professional Geologist (CPG) with a minimum of 5-years experience in karst studies and engineering geology;

A statement of qualifications, signed and sealed, with supporting documentation (e.g. resume, curriculum vitae, etc.) should be part of the assessment report, including a statement specifying that the investigator meets the definition of a karst professional investigator as defined above.

It is important to understand that a P.E. license does not necessarily qualify an individual to be a karst investigator, or make recommendations regarding engineering solutions for karst geohazards. By the same token, many licensed geologists have never had any formal training or experience with engineering geology or geotechnical engineering. Specific expertise and experience dealing with karst issues is the most critical factor in designating an individual as a karst professional investigator.

An example of a well-written definition of a qualified karst investigator can be found in the Clarke County Va. Karst Plan Requirements:

Geotechnical Engineer - A Virginia registered professional engineer (PE) engaged in the practice of Geotechnical Engineering, or a Virginia Registered Professional Geologist (PG) who is engaged in the practice of engineering geology.

Although the definition of a "geotechnical engineer" is somewhat of an exaggeration in the above statement of qualifications, (i.e. an "engineer" needs to be licensed to be called such, and a licensed geologist is not an engineer although in the Clarke County regulation they are defined as such), the intent is admirable. Where the Berryville, Clarke County Va. statute falls short is not requiring specific experience in karst. Thus, a PE or CPG with little or no experience in karst geology could theoretically sign and seal an investigation, within which recommendations have been made that could be poorly informed at best, or lead to disastrous consequences at worst.

Finally, it cannot be emphasized more that karst is not a uniform geomorphological process, and varies considerably from region to region. A geologist or engineer with experience in the relatively weak and collapse-prone Tertiary carbonates of Florida may not be familiar with issues affecting the stronger and more competent Paleozoic carbonates of the Appalachian region, or the Mesozoic carbonates of the Texas plateaus. Thus, it is important that an investigator have specific experience in the regional karst where the assessment is being conducted.

\section{Definitions and Terminology}

The lexicon of karst literature is among the most varied and complex of the earth sciences, due to much of the seminal work being carried out in non-English speaking countries. Thus, myriad terms are often used for the same structure (e.g. swallet, insurgence, sinking stream, ponor, swallow hole, perte de riviere, all of which refer to the same feature). As much of karst description is typological in nature, the specific terms that are used to describe a feature must be consistent and understandable to both a professional reviewer and a non-technical user. Thus, each assessment should include at least a brief glossary wherein the specialized terms being used are explained and clearly defined. The source reference for this glossary should be the publication "A Lexicon of Cave and Karst Terminology with Special Reference to Environmental Karst Hydrology" published by the U.S. Environmental Protection Agency (Field, 2002).

\section{Recommended Scope of Services}

The geologist or other qualified individual shall undertake an inspection of the site area and prepare an investigation report which shall include (but not be limited to) the following elements:

a. Site description and terrain analysis; 
b. Description of published soils and underlying bedrock and comparison to onsite observations;

c. Delineation of major surface drainages and water features;

d. Location and delineation of major karst features and drainages including, but not limited to: sinkholes (both active and incipient), caves, insurgences (swallow sinkholes), resurgences (springs), losing streams, and potential for "covered" karst (i.e. sinkholes lying beneath soils cover);

e. Inferred locations of shallow bedrock (based on evidence from rock outcrops)

The assessment should include a summary of findings, with any recommendations made by the investigator for additional studies which may include electrical resistivity studies, seismic studies, subsurface borings, or any other appropriate method to determine if the proposed development may have negative impact on human health, safety, property or the environment.

The findings should be summarized as follows:

No evidence of karst features - If the investigator finds that the site is not underlain by soluble bedrock, or there is no evidence of karst features (including "covered" karst or pinnacled bedrock), they shall so indicate.

Evidence of karst features - In cases where the investigator finds evidence of karst features which would be impacted by development, detailed subsurface investigations shall be required within a 100-foot radius of all areas where karst features were identified, and along any linear trend of three or more aligned features. For sinkholes, the 100foot radius shall be measured from their discernable edge. At the completion of the investigation the investigator should prepare a Karst Management Plan and the developer directed to follow the specific recommendation embodied therein.

Presence of karst features on the site which will not be impacted - If no karst features are to be affected by the planned development, there will be no need to submit a stand alone karst plan. A statement should be included in the Karst Site Assessment certifying that no features will be impacted.

\section{Description of the Scope Elements}

Site Description and Terrain Analysis

The investigator should describe the site, based on examination of the closest topographic mapping available and subsequent field observations. At a minimum, the site topography should be referenced using the USGS 7.5-minute series topographic quadrangle; however it is recommended that 2-foot contour maps or LIDAR (Light Detection and Ranging) be utilized if available (see Figures 2 and 3). In addition, stereoscopic aerial photograph pairs and aerial photo fracture trace analysis may be utilized. Any karst features visible on the topographic map and remote sensing resources (i.e. caves entrances, sinkholes, closed depressions, etc.) should be noted and examined during the field reconnaissance phase of the assessment.

The site description should also include a careful delineation of the property's metes and bounds, and its current use and condition (i.e. vacant land, agricultural land, developed land etc.). Any proposed changes to the site, especially development plans, should be noted and explained in the assessment report.

\section{Description of Soils and Bedrock Geology}

The investigator should access the National Resource Conservation Service soil maps for the project site using the web soil survey: http://websoilsurvey.nrcs.usda.gov/app/HomePage.htm Soils data should be examined for the site and adjacent properties, with particular emphasis on the parent materials

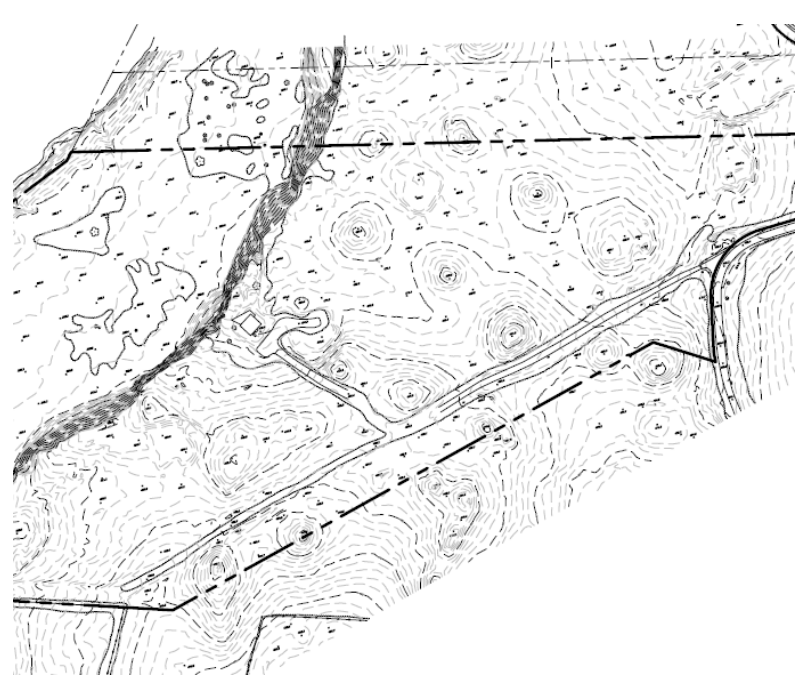

Figure 2. Two-foot contour map of a project site, showing a series of closed depressions (sinkhole) in lineaments. 
(i.e. whether the soils are residual or transported), their hydrologic characteristics, and textural analysis. Certain soils are noted in NRCS survey data as being "prone to sinkhole formation". These soils should be noted and indicated in the final report. Areas underlain by these soils should be carefully examined even if no closed depressions or sinkholes are noted in the terrain analysis.

Understanding the soils is critical to predicting whether sinkholes will form after a site has been "stripped and grubbed" (i.e. cleared), as highly cohesive soils can often create a "covered" or mantled karst condition where numerous soil-filled or open conduits are hidden beneath the seemingly homogeneous soils cover. Upon removal of the vegetation, the soil will begin to ravel, and previously undetected sinkholes will begin to form.

Bedrock geology should be determined by referencing the highest resolution geological mapping available, ideally at a 7.5-minute topographic quadrangle level. This information can be found by accessing the USGS National Geologic Map Database (ngmb.usgs.gov) or the websites of the local

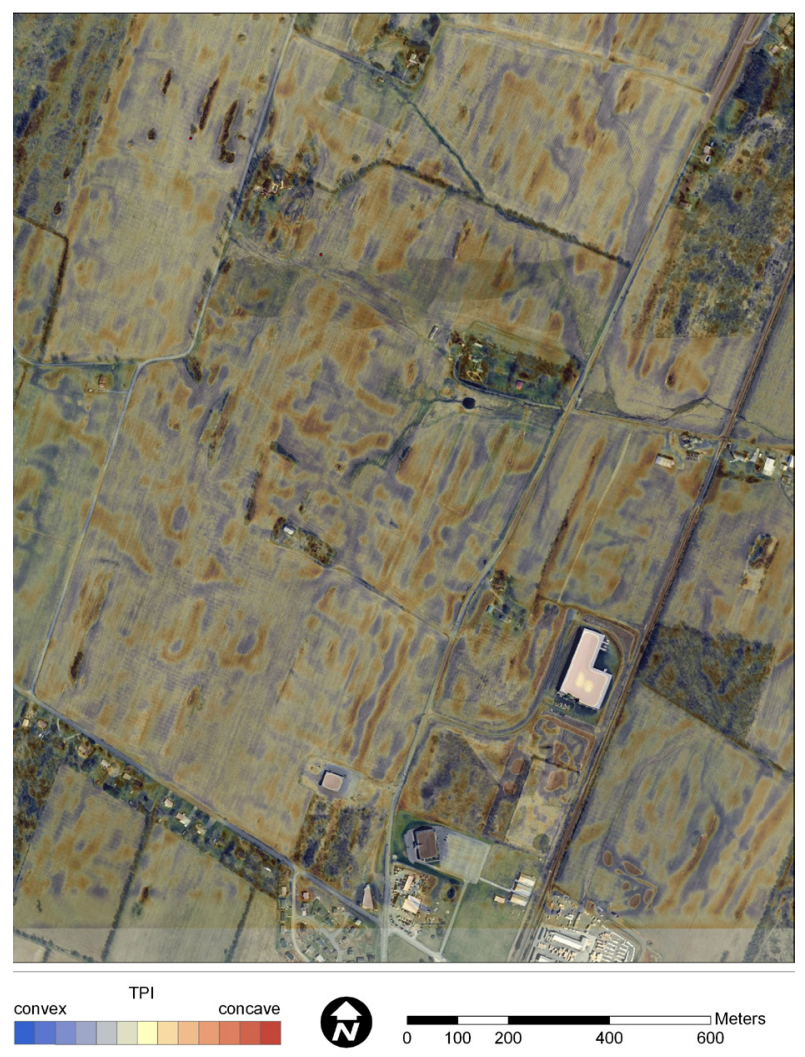

Figure 3. Topographic Position Index (TPI) showing local topographic concavity and convexity derived from a $7 \mathrm{~m}$ LIDAR elevation model and overlain on aerial imagery. state geological survey. Dip and strike of the bedrock, and any significant structural features (mapped faults, anticlines or synclines, etc.) should be noted.

Field inspection should attempt to verify the mapped soils and bedrock by comparison to the available descriptions. Based on their field observation, the investigator should note whether or not the soils and bedrock conform to the published description(s). If they compare favorably, then no further explanation is required. If they do not, then a detailed description of the differences should be provided.

\section{Description of Surface Drainages and Water Features}

The investigator should determine the drainage patterns at the site by examination of the topography. The investigator should also check to see if any publicly available hydrological assessments have been performed for the region of interest by state or federal entities.

The analysis of drainage patterns should determine if the site has outlets (i.e. if drainage is directed offsite) or if it is internally drained as these factors can profoundly affect site planning, especially in regards to stormwater management. Drainages to sinkholes should be clearly delineated (Figure 4).

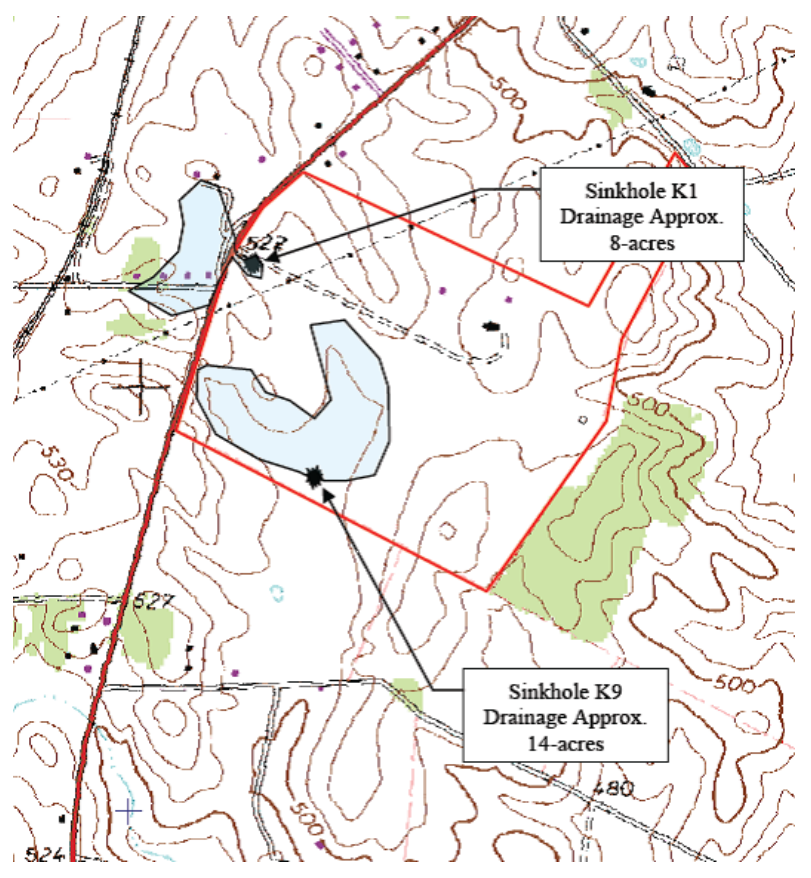

Figure 4. Example drainage map showing sinkhole drainage areas. Note that the drainage area for sinkhole K1 is primarily outside of the site boundary (red line). 
The locations of perennial springs, streams and water bodies (lakes, pond, etc.) should be noted. The locations of losing streams (i.e. streams that lose water to the subsurface through their bed), gaining streams, and sinking streams should be carefully noted.

\section{Location and Delineation of Karst Features}

Prior to the field observation phase of the assessment, the investigator should access available karst and cave survey databases to determine if any features have been previously located or mapped at the site or on adjacent areas. The National Speleological Society (NSS) has survey committees in most states where there are a significant number of caves, and although the databases of these surveys are technically proprietary, the surveys will share these data with legitimate investigators to assist in conservation and protection efforts. In addition, many karst features have been located by the United States Geological Survey (USGS) and the various State Geological Surveys, and are shown on surficial geology maps, karst survey reports, and other publications. Various state surveys have also published compendiums of cave locations and descriptions in book form, but these publications are seldom complete and need to be supplemented by data that has been collected from the regional NSS surveys. The NSS also has made available through their publication bookstore numerous county level cave surveys which should be accessed if pertinent to the area of interest.

Finally, it is extremely helpful to interview the land owner and/or neighbors regarding the location of any karst features known to them that may exist on or near the survey area. Residents may also know of sinkholes that have been filled or obliterated, cave entrances that have been physically closed, or other features not readily observable during the site inspection. They may also have useful information regarding locations of wet weather springs, seeps, or ephemeral karst lakes and ponds (turloughs) resurgences that are not present during dry weather periods. Alternately, residents may know of locations where water consistently collects and infiltrates into the subsurface. Although anecdotal, it is to the investigator's advantage to examine and verify these observations.

Once the potential locations of karst features have been accessed and noted, the investigator can begin the task of field survey. The site should be examined by a systematic traverse, and each previously identified karst feature should be examined in the field as follows:
Closed Depressions/Sinkholes - The locations of any closed depression (CD) or area of closed descending contours should be located and examined. The investigator should describe the feature, noting the following parameters:

1. What is the general shape of the CD?

2. Is the $\mathrm{CD}$ actively forming (i.e. are there soil tension cracks around the perimeter of the structure?) or has most of the soil already raveled into the subsurface? (See Figure 5A,5B)

3. Is the CD soil-lined or is there exposed bedrock? (Figure 5C,5D)

4. Are there mature trees in the structure? What are the estimated ages of the trees? (Figure 5C)

5. Does the CD have a "throat" or opening(s) leading into the subsurface? (Figure 5D, 5E)

6. Is there any sign that the CD floods or that it is an estavelle $^{1}$, such as watermarks, saturated soils, or outflow channel? (see Figure 6A, 6B)

7. Is the $\mathrm{CD}$ in a topographic position such that it receives drainage from the surrounding area?

8. If the answer to question 7 is "yes", does the CD have an obvious drainage channel leading into it, or does it accept only diffuse sheet flow drainage?

The CD should then be measured and delineated. This can be done by the investigator using a hand-held GPS unit, or the structure can be marked ("flagged") in the field and surveyed at a later time. The structure's approximate depth and circumference should be determined as closely as possible and noted, as well as any "nesting" of smaller depressions within the larger ones.

The investigator should be aware of any area where there are signs that water is actively infiltrating into the surface, as this may be an indicator of a subsurface conduit that is soil-filled but receiving drainage (see Figure 7). In this regard, distinct changes in vegetation can be a clue if topographic is slight or absent. These areas should be carefully noted and investigated if they are to be impacted by proposed site development, as they can be the site of sudden and catastrophic subsidence if not managed properly.

Caves - There is a cross-over between caves and closed depressions and sinkholes, as cave entrances are often located within the latter. However, a "cave"

'A sinkhole which acts as a spring during groundwater highstand conditions, and an insurgence during low stand conditions. 
is traditionally defined as an air-filled opening into the subsurface large enough to allow the passage of a human being. As caves are frequently the home for rare, threatened and endangered species (RTES), often contain important cultural and historic resources, and are environmentally sensitive, it is imperative that they be managed, conserved and protected.

The investigator should attempt to locate and examine any mapped or reported caves on the site. Locations of caves with entrances off-site that may extend beneath the site being studied should also be noted. The majority of significant caves have been mapped, and the investigator should request maps for any onsite or adjacent caves from the regional speleological survey of the NSS. A plan view of the cave showing its route beneath the site is useful to developing a karst management plan. A profile

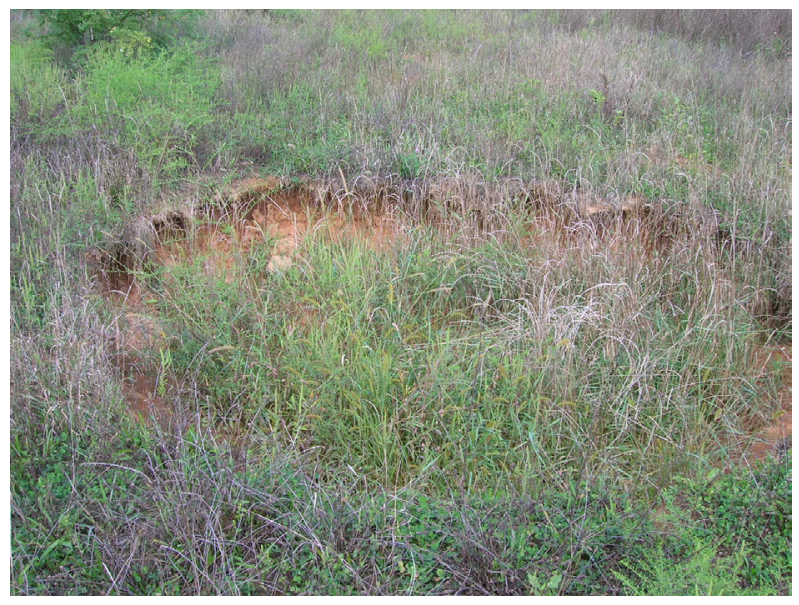

Figure 5A. Actively forming cover collapse sinkhole in granular sediments.

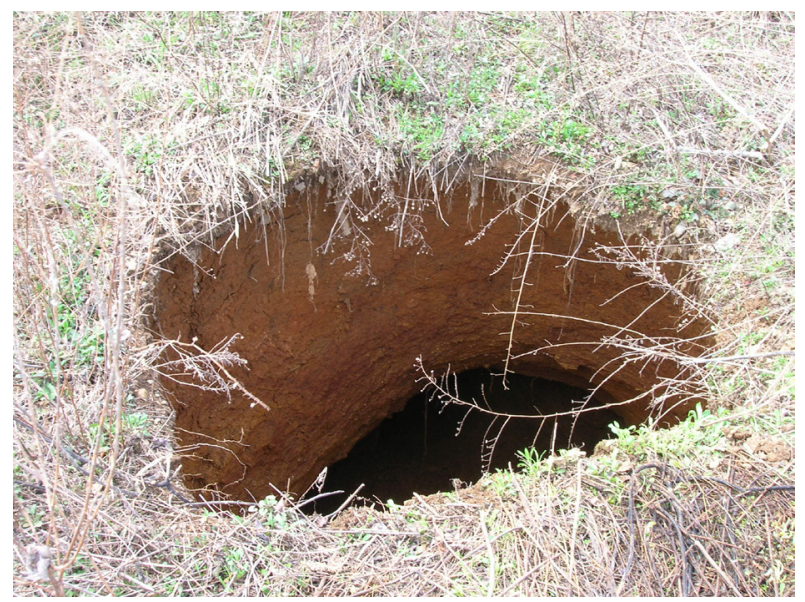

Figure 5B. Actively forming cover collapse sinkhole in cohesive, fine-grained sediments.

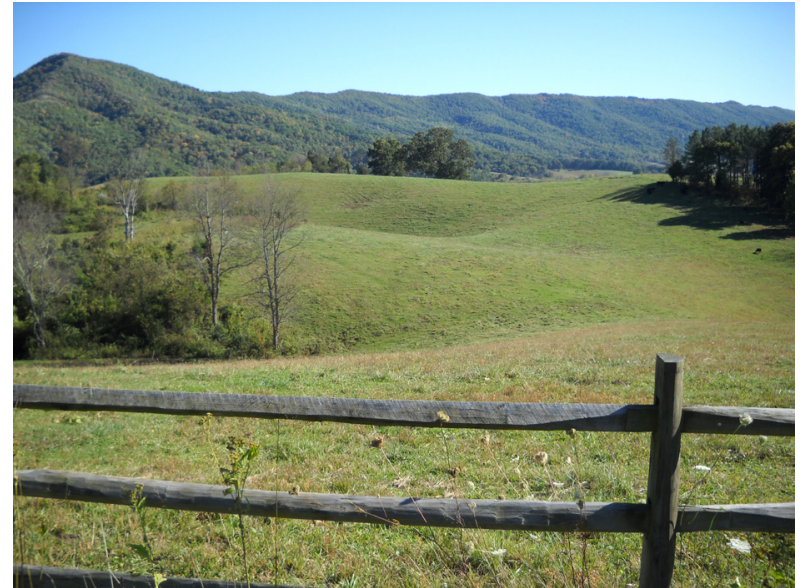

Figure 5C. Mature, stable sinkholes in cohesive soils.

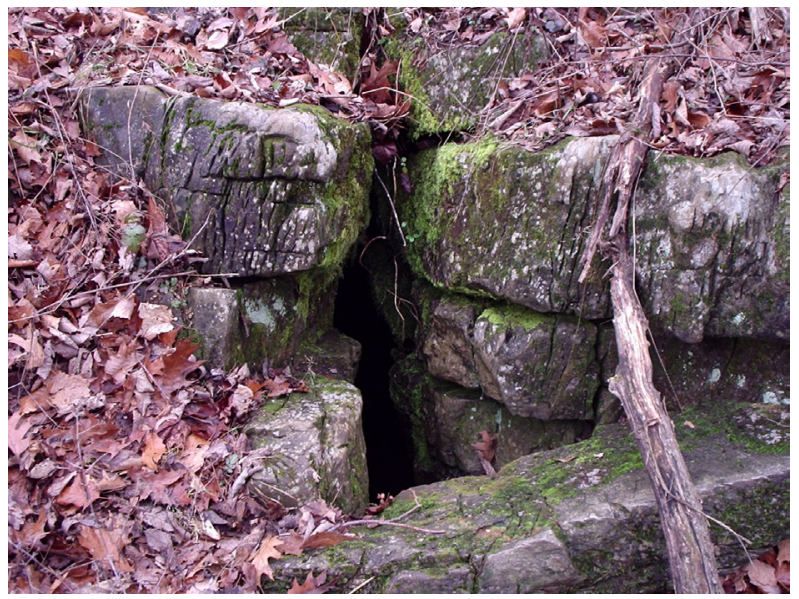

Figure 5D. Mature, rock-walled sinkhole with open "throat" (i.e. cave entrance).

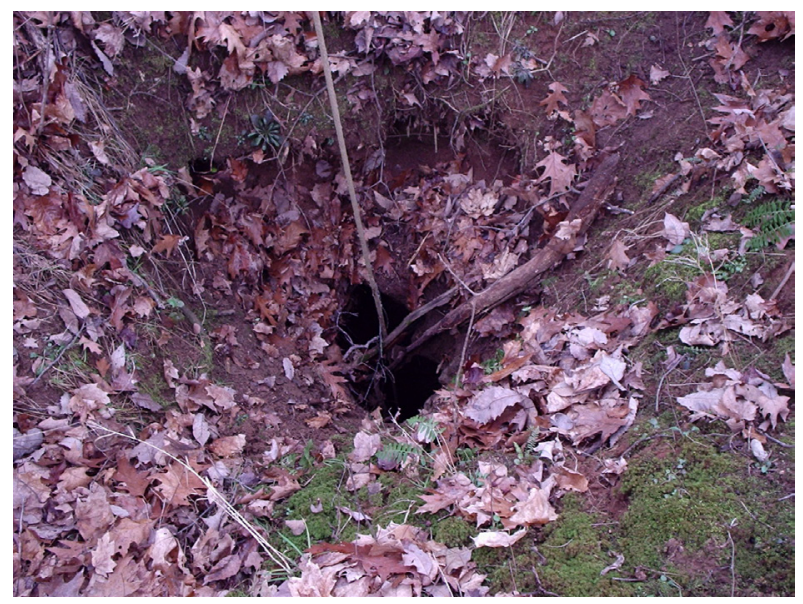

Figure 5E. Soil-bottomed sinkhole with open "throat". A $40^{\prime}$ deep vertical cave lies below the opening. This type of structure is sometimes called a "natural trap". 


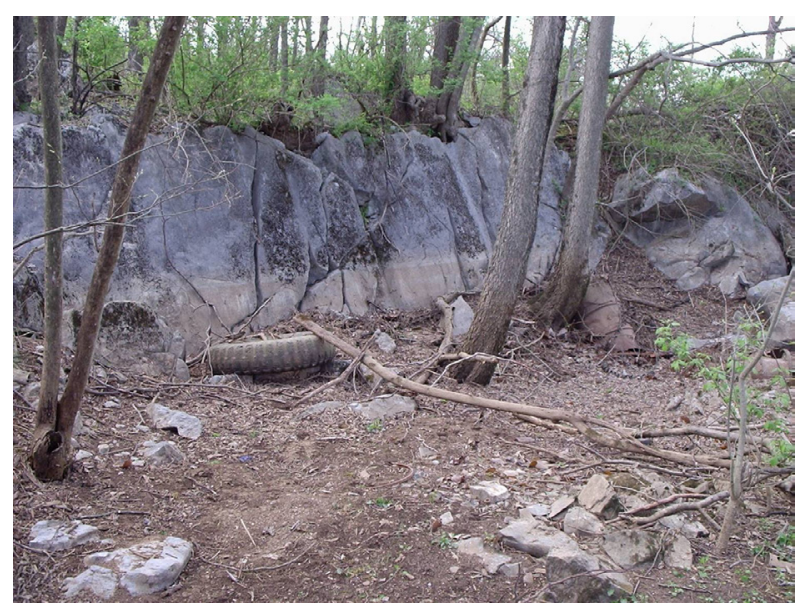

Figure 6A. An estavelle in groundwater low-stand conditions. Note the tell-tale water mark along the rock wall of the structure.

view, showing the cave's depth below the surface, is also important, as caves that are located close to the surface can present a risk to planned development. In contrast, shallow caves can be more readily impacted by releases of contaminants, redirection of surface drainage, and grading activities (e.g. blasting, hoe-ramming, etc.).

As a cautionary note on-site caves should not be entered by the investgator unless they are an experienced spelunker and familiar with the methods and techniques of cave exploration. Caving is an inherently dangerous activity, and should never be done alone and/or without the proper equipment. The local chapters of the NSS,

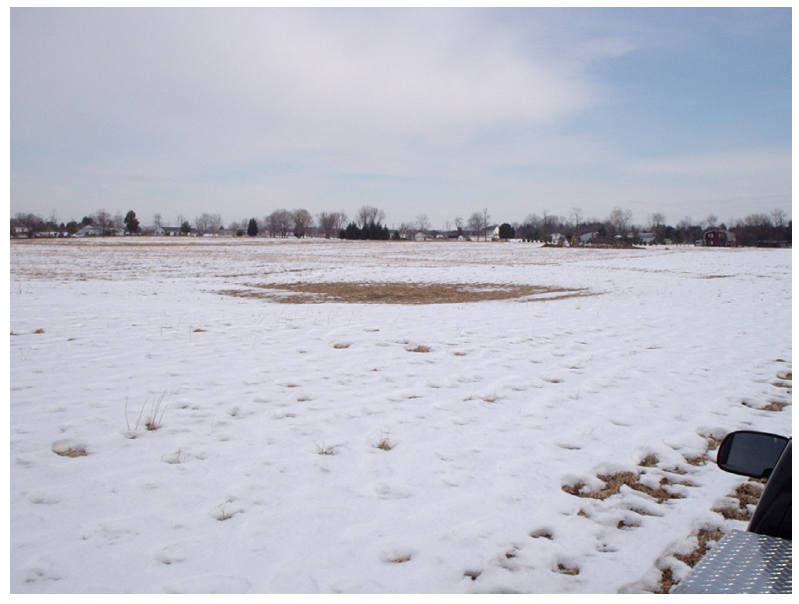

Figure 7. An area of snowmelt marking a closed depression where water was actively infiltrating into the subsurface. This depression had a relief of less than 2-feet below the surrounding terrain and was not indicated on the site civil engineer's 2-foot contour map. Subsequent Electrical Resistivity Survey (ERS) showed the presence of a soil-filled throat in the bedrock below the structure that was actively channeling surface drainage into the subsurface.

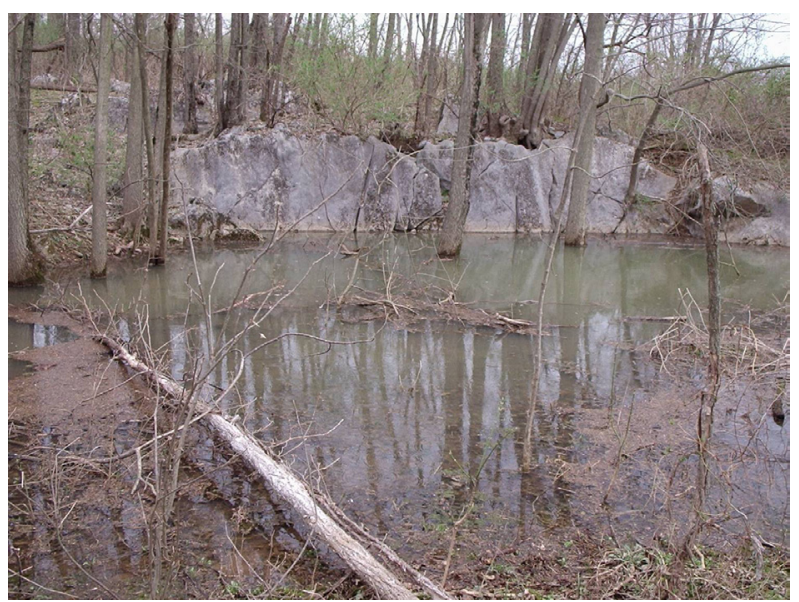

Figure 6B. The same structure as shown in Figure 6A during groundwater high stand conditions. When this photograph was taken the estavelle was an active, ephemeral spring with an outflow measured at $60 \mathrm{gpm}$.

called "grottoes", generally are glad to help with an assessment by exploring, photographing and mapping a new or unexplored cave.

Karst Drainages and Hydrology - Places where water is either entering the subsurface through a solution feature, or exiting the subsurface through a resurgence (spring) should be located and examined. The locations of perennial springs are generally shown on 7.5-minute series USGS topographic maps. In addition, the landowner or neighbors may have knowledge of springs that have not been mapped or previously marked. Spring flow rates should be measured using accepted hydrological methods and reported.

Insurgences, sinking streams or valley drains (open throat sinkholes that receive surface drainage through a well-defined channel) should be located and described. It should be noted that if a site is internally drained, and a pre-existing insurgence is proposed for use as a discharge point for stormwater, that it falls under the definition of a Class V Injection Well, according to regulations established by the US EPA, and should be registered with the regional EPA office. Many states have their own regulatory requirements for stormwater disposal into sinkholes as well, and these should be checked and referenced if applicable.

The determination of subsurface drainage patterns in karst is a technically demanding and specialized activity, and is typically beyond the scope of a preliminary karst assessment. However, in many well-studied karst regions, major drainages and features have been delineated 
using dye tracing techniques, and the literature should be searched by the investigator to see if any previous studies have been conducted in or near the area where the assessment is being performed. If ground water monitoring is to be included in the scope of work, then the investigator should employ the techniques embodied in the US EPA guidelines for groundwater monitoring in karst (Quinlan, 1989).

Finally, it should be noted that although they are not natural features, abandoned quarries, drilled wells and hand-dug wells all qualify as openings into the subsurface, and often have direct connection to the phreatic aquifer. As such, these features should also be included in any comprehensive karst assessment.

Covered or Mantled Karst - In many karst settings there is often a relatively thick stratum of cohesive soils lying above the solution-modified bedrock, and these soils can bridge over even air or water-filled conduits. Often there are no obvious karst features to be seen in this type of natural setting, however upon removal of the vegetation and topsoil (i.e. stripping and grubbing) during the preliminary stages of grading a site, cover collapse sinkholes will rapidly form where there seemingly were none before (Figure 8).

Nevertheless, the identification of covered karst is often dependent upon the investigator's knowledge of regional

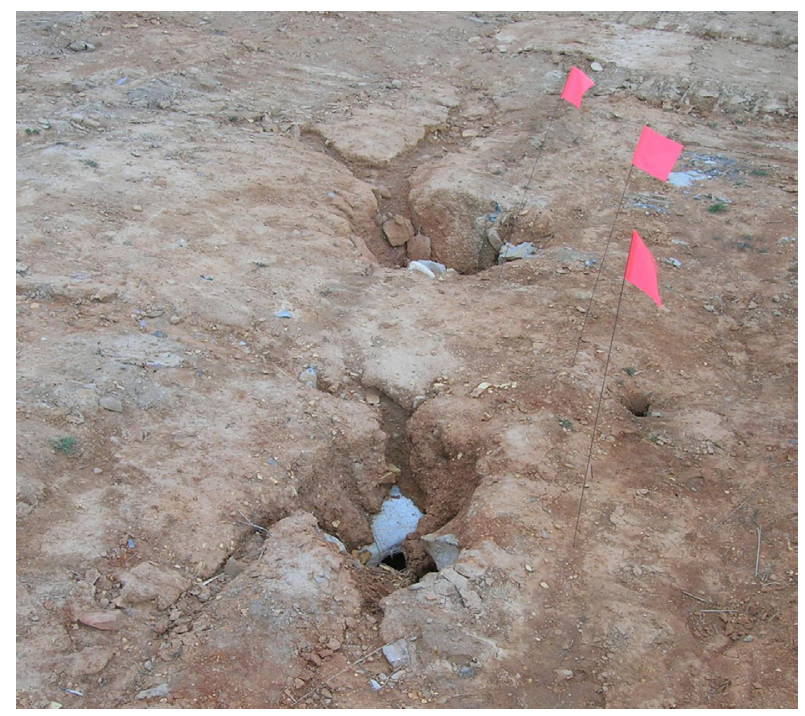

Figure 8. A pair of cover collapse sinkholes that opened at a site under development after the vegetation and topsoil was stripped. Open throat, air-filled conduits in the bedrock were located at the bottoms of both of these features. geology, soils, and prior experience with sites in similar geological settings.

Although it can be difficult to locate specifically, if the site is located in an area that the investigator suspects where there may be covered karst conditions present, this should be clearly indicated in the assessment report as covered karst can cause significant delays in construction, and increase the costs of site development well beyond the client's expectations. Therefore, it is strongly recommended that the investigator include a statement in the report's opinions and recommendations section as follows:

As indicated in this report, the bedrock and overlying soil below the site are susceptible to sinkhole development, and karst features are likely hidden beneath the existing soil stratum. Risk associated with sinkhole formation can be minimized during development with proper foundation design and construction, and the control of site hydrology. The Owner/Developer must recognize, however, that a risk of sinkhole-induced damage to foundations, floor slabs, and pavements does exist. The Owner must evaluate the risks and attendant costs of development, and must be willing to accept them.

\section{Location of Shallow Bedrock}

The karst terrain is notorious for the presence of shallow bedrock, often with large areas of exposed ledges and shelves. This is particularly problematic due to the fact that much of the carbonate rocks can be resistant to scaling or scarping, and must be either rammed or blasted during the grading process. Areas of shallow or surface exposed bedrock need to be clearly delineated and described in the assessment report.

In areas where the bedrock is steeply inclined, differential solution activity can produce a "pinnacled" bedrock surface, often with exposed bedrock ledges and deep intervening "cutters" in between containing residual soil (Figure 9).

The ledge and cutter terrain is often not considered a sensitive environmental feature by site developers or regional planners, however it can present a significant impact to the subsurface environment if not managed properly. Surface water can migrate rapidly along the interface between the bedrock and the soil filled interstice. During periods of extended drought, the soil 


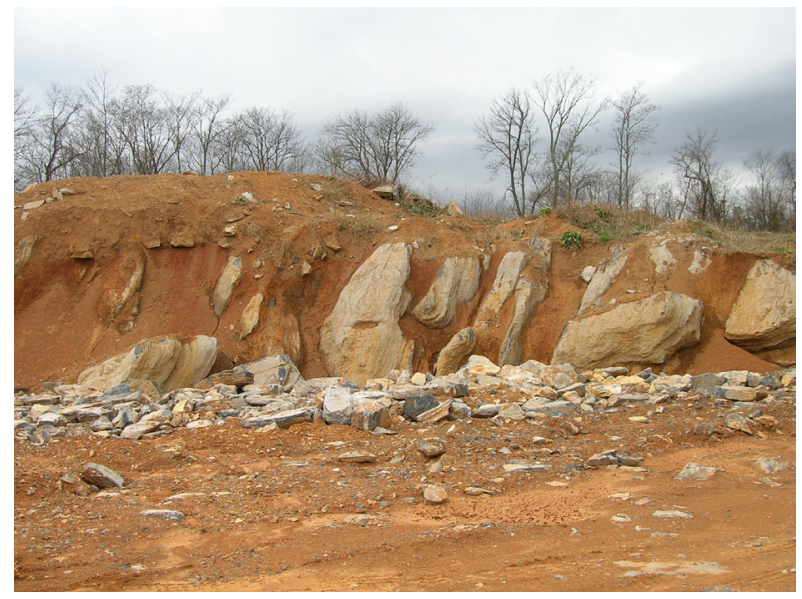

Figure 9. Excavated site cross-section showing pinnacled bedrock with intervening soil-filled "cutters".

fills in the cutters can shrink, and open voids (soil cracks) will form, allowing surface water to plunge into the subsurface, often with direct connection to the phreatic aquifer (Figure 10). Turbulent flow along the interface can also begin the process of soil raveling, sometimes resulting in the sudden formation of sinkholes. In many regions, especially those with cohesive, shrinkswell prone clays, there is often a condition informally referred to as "sinkhole weather" which is characterized by extended dry weather or drought punctuated by periods of heavy rain. Sinkholes will often form when these conditions are present.

Finally, areas of a site designated for storm water management BMPs, especially extended detention and/

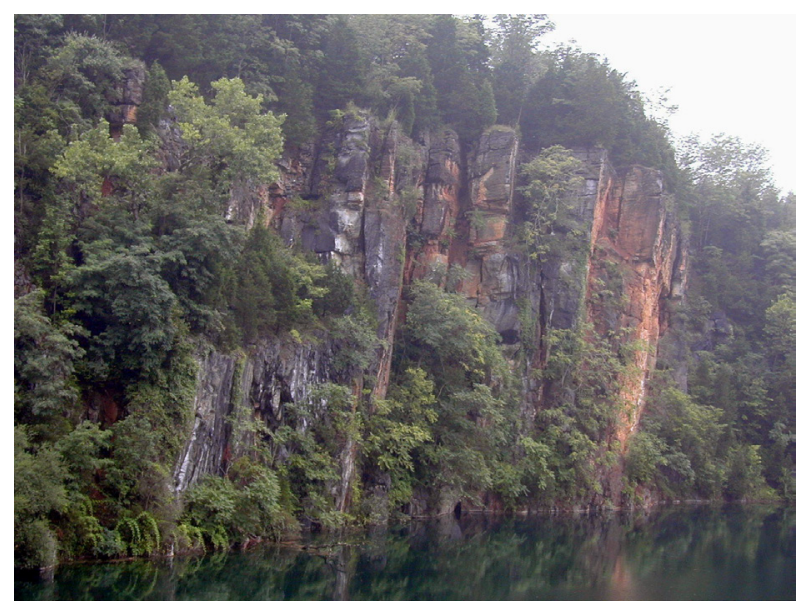

Figure 10. The epikarst exposed in an abandoned limestone quarry wall, showing steeply-angled open solutionmodified fractures extending down to the quarry lake. The lake is representative of the local phreatic base-level, and demonstrates how contaminants and surface water can readily migrate to the underlying water table. or retention ponds or impoundments, must be carefully examined for the presence of pinnacled bedrock.

Exposed pinnacles (Figure 11) can lead both to uncontrolled infiltration of contaminants into the subsurface from the base of the pond, or in the worst case scenario, catastrophic development of sinkholes into which the entire contents of a pond (i.e. water, collected sediment and entrained contaminants) can be disgorged. If pinnacled bedrock is present in these areas the users of the assessment should be made aware of the condition and the risks associated with it.

Exposed pinnacles (Figure 11) can lead both to uncontrolled infiltration of contaminants into the subsurface from the base of the pond, or in the worst case scenario, catastrophic development of sinkholes into which the entire contents of a pond (i.e. water, collected sediment and entrained contaminants) can be disgorged. If pinnacled bedrock is present in these areas the users of the assessment should be made aware of the condition and the risks associated with it.

\section{Follow-Up Studies}

If the planned site development will impact karst features at a site, then follow-up studies will inevitably be necessary to thoroughly characterize the impact and help the developer and regional planners understand the risks involved. These studies may include detailed subsurface investigations such as geophysical exploration (e.g. electrical resistivity survey, seismic survey, microgravimetric survey, etc.), borings, track drill exploration, or any combination of the methods. It should be noted that geophysical studies, in particular

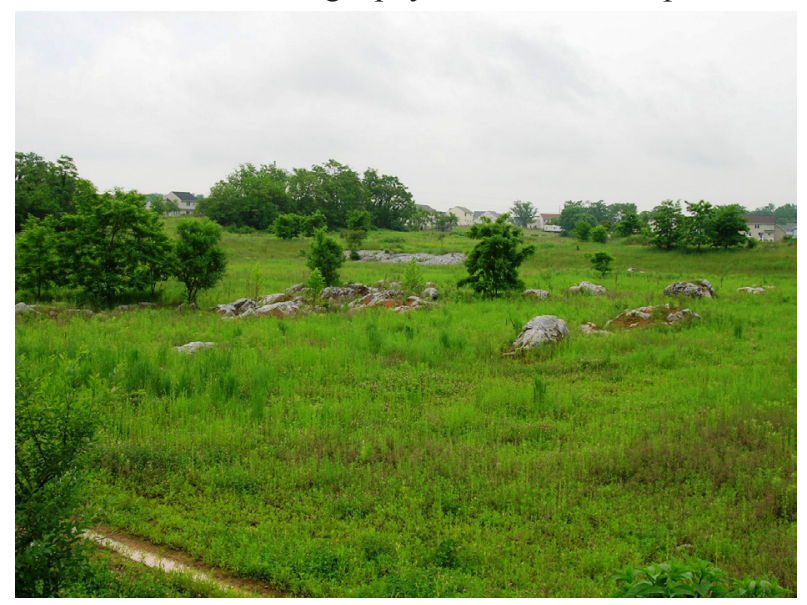

Figure 11. Exposed bedrock pinnacles located in the base of a stormwater detention structure in West Virginia. 
electrical resistivity survey (ERS), require experienced interpretation which can often be very subjective. In addition, the use of ERS or other geophysical methods without attendant rock probes (coring, track drill, etc.) can often be misinterpreted; however coring or air track investigations carried out without any supporting geophysical evidence of subsurface structures can be wasteful and expensive with little to show for the effort. The two methods should always be used in concert with one another.

\section{The Karst Management Plan}

A karst management plan should be prepared for any sites where there is evidence of karst features (i.e. sites upon which karst features are fully or partially located, and/or which drain to offsite sinkholes).

The Karst Management Plan shall include (but not be limited to) the following elements:

a. A karst feature inventory showing the areal extent of each structure, and a (minimum) 100 foot radius buffer area around the feature;

b. A topographic map prepared at a maximum 2 -foot contour interval, with spot elevations sufficient to determine low points or discernible edges;

c. A plan prepared by a Geotechnical Engineer to ensure structural stability of principal structures proposed within 100 feet of a sinkhole or other significant karst feature. The plan shall identify tests that will be completed to determine subsurface conditions.

d. Mitigation recommendations for each karst feature requiring this action. All sinkholes identified prior to construction should be either mitigated or separated from construction. Mitigation should be carried out under the careful observation of the karst professional investigator to confirm site conditions are as predicated in the karst assessment study, and to make necessary modifications to mitigation measures in the event actual site conditions differ from the estimated conditions presented in the study.

e. The management plan should be reviewed and approved by the county engineering and/ or planning staff prior to approval of site development or issuance of plats.

\section{Closure}

It is our hope that this article may serve as a template to assist investigators in conducting comprehensive preliminary karst assessments, and helping jurisdictional regulators, engineers and legislators in determining the minimum elements that should be expected in a site evaluation.

It should be emphasized that the scheme presented herein is not intended to serve as a substitute for detailed subsurface investigations, or to supersede any existing karst regulations or codified protocols.

\section{References}

ASTM Standard E1527-05, "Standard Practice for Environmental Site Assessments: Phase I Environmental Site Assessment Process," ASTM International, West Conshohocken, PA, 2005, http://www.astm.org. Available from: http://dx.doi.org/10.1520/E1527-05

Code of Clarke County, Virginia. 1997. 1st Revision and Codification of the General Ordinances Passed on or before February 6, 1974. Recodified and Adopted October 21, 1997.

Currens, J. C., 2009. Model Ordinance for Development on Karst in Kentucky. Kentucky Geological Survey, University of Kentucky, Lexington, KY.

Field, M. 2002. A Lexicon of Cave and Karst Terminology with Special Reference to Environmental Karst Hydrology. EPA/600/R-02/003, U.S. Environmental Protection Agency, Washington, DC.

LaMoreaux, P. E., LaMoreaux, R., 1998. A history of karst studies from: From Stone Age to the present. Focus, Summer98, 45(2), 6 pp.

Loudoun County Facility Standards Manual, 2010, Chapter 6.000: Soils, Geotechnical and Hydrogeological Reviews. Adoption Date 2/17/2010.

Model ordinance [Internet]. 2012. [Place of publication unknown]: Karstportal.org; Available from: http://www.karstportal.org/search/node/ ordinances.html.

Moser, P.H., Hyde, L.W. 1974. Environmental Geology: An aid to Growth and Development in Lauderdale, Colbert, and Franklin Counties, Alabama. U.S., Tuscaloosa, Alabama: Geological Survey of Alabama State Oil and Gas Board, 45 p.

Orndorff, W., Fagan, J., 2001. Towards a Comprehensive Sinkhole Classification Scheme for Land Use Planning. 2001 National Cave and Karst Management Symposium (abstract only). 
Quinlan, J. F. 1989. Ground-Water Monitoring in Karst Terranes: Recommended Protocols and Implicit Assumptions. EPA 600/X-89/050, U. S. Environmental Protection Agency, Environmental Monitoring Systems Laboratory, Las Vegas, Nevada.

Rauch, H. W., Werner, E. B., editors. 1974. Proceedings of the Fourth Conference on Karst Geology and Hydrology.

Teetor, A., Clarke County Karst Plan Requirements. Clarke County, VA. Adopted 2/17/04.

Zötl, J. 1974. Kartshydrologie. Wien and Noew York: Springer-Verlag, $291 \mathrm{p}$. 